\title{
Co-Simulation - An Empirical Survey: Applications, Recent Developments and Future Challenges
}

\author{
Gerald Schweiger $^{1 *}$, Georg Engel ${ }^{1}$, Josef-Peter Schöggl ${ }^{2}$, Irene Hafner ${ }^{3}$, \\ Thierry S. Nouidui ${ }^{4}$, Cláudio Gomes ${ }^{5}$ \\ 1 Institute of Software Technology, Graz University of Technology, Inffeldgasse 16b/ll, 8010 Graz, Austria; \\ *gerald.schweiger@tugraz.at \\ ${ }^{2}$ Christian Doppler Laboratory for Sustainable Product Management, University of Graz, Merangasse 18, 8010 \\ Graz, Austria \\ 3 dwh GmbH Simulation Services and Technical Solutions, Neustiftgasse 57-59, 1070 Vienna, Austria \\ 4 The United African University of Tanzania, P.O. BOX 36246, Dar Es Salaam, Tanzania \\ ${ }^{5}$ Aarhus University, Åbogade 34, 8200 Aarhus N, Denmark
}

SNE 30(2), 2020, 73-76, DOI: 10.11128/sne.30.sn.10516

Received: December 5, 2019 (Selected MATHMOD 2018 Postconf. Accepted: Publ.; Accepted: January 20, 2020

SNE - Simulation Notes Europe, ARGESIM Publisher Vienna, ISSN Print 2305-9974, Online 2306-0271, www.sne-journal.org

Abstract. This article describes the first results of an empirical survey on co-simulation conducted with over 50 experts in this field. In the last decades, cosimulation has become an important tool to meet challenges emerging from the increasing complexity of systems and the need for efficient collaboration between experts in different disciplines. However, research on this topic has been motivated by varying fields of interest and developed with different perspectives on application and thus lead to different definitions and emphases within this topic. The present survey aims to clarify some of these different perceptions and open research fields.

\section{Introduction}

In recent decades, simulation-driven development has increasingly become established as a central method in industry and academia. This is leveraged by computational advances, like the recent emergence of equationbased modelling languages, which offers new possibilities compared to block diagram modelling using imperative programming languages [16]. Classically, systems are modelled in a single tool, which is referred to as monolithic approach. With the increased complexity of systems and the need for linking several domains in one model, monolithic approaches have restrictions: sometimes it is not possible to simulate a complex system in a single tool, but even if it is possible, very often there are more suitable tools available for different subsystems. Ideally, every subsystem is modelled in a tool that meets the particular requirements for the domain and the structure of the model. Thus, the need for coupling different tools is a pragmatic one. Co-simulation is an approach to enable a simulation of complex single or multi-domain systems that consists of at least two subsystems (modelled in different tools) which solve coupled (algebraic) differential systems of equations ([5]). An overview of co-simulation approaches and tools, research challenges, and research opportunities are presented e.g. in the references $[12,1,8,5,13]$. The proposed empirical survey aims to merge different views of heterogeneous communities which are working in the field of co-simulation, on the state of the art, research gaps and future challenges.

\section{Method}

As a methodological foundation of the empirical survey, the Delphi method is adopted. The Delphi method is a forecasting technique that bases on the collection and compilation of expert knowledge from a panel of experts in a multi-stage process $[3,6]$. It fosters group communication which is intended to deal with complex problems, particularly for the case where there is insufficient knowledge, lack of historical data, or lack of agreement found within the studied field [9]. The Del- 
phi method is also conceived to be useful particularly for solving interdisciplinary research problems in a heterogeneous environment [11]. Moreover, it enables determining probable future scenarios. We aim at integrating at least 30 experts in our Delphi study, because despite the lack of a mandatory minimum requirement, [2], for instance, states that 15-30 participants are adequate for studies involving experts with a homogenous expertise background. For selecting the sample of participants, a Knowledge Resource Nomination Worksheet (KRNW) is used as a guideline [4, 9]. The Delphi study forms two rounds. The first round comprises a mix of open-ended and closed-ended questions. The second round includes only closed-ended questions that are formulated based on the results of the first round. In addition to these standard questions, an additional quantitative analysis of the strengths, weaknesses, opportunities and threats (SWOT) of co-simulation utilizing the Analytic Hierarchy Process (AHP) is conducted. The SWOT-AHP method was introduced by [7] to increase the effectiveness of a primary SWOT analysis as a decision-making tool [10]. In this study, the SWOTAHP method is utilized to enrich the results of the Delphi study by providing an additional and new perspective on the current state of co-simulation.

The questionnaire for the first round of the Delphi study consisted of four parts:

1. The roots of co-simulation. This includes questions about different origins for co-simulation, concepts, wording and scientific and industrial communities.

2. Theoretical questions. Included are questions regarding the state-of-the-art, research gaps and open issues within continuous, discrete and hybrid co-simulation.

3. Functional Mock-Up Interface (FMI). Since FMI is already widely used and it is a promising candidate to become the standard for industry and academia, a section with specific FMI related questions was designed.

4. Questions related to an overall SWOT analysis of co-simulation.

At this stage of the survey, the first round of interviews and the expert selection for the second round have both been completed; more than 40 experts have already committed to participate in the second round.

\section{Preliminary results}

In the first round of interviews, experts had to select three factors for the categories 'Strengths', 'Weaknesses', 'Opportunities' and 'Threats'. In the following, we present the results for the pre-selection of SWOT factors in hierarchical order.

\section{Strengths:}

1. Every sub-system can be implemented in a tool that meets the particular requirements for the domain, the structure of the model and the simulation algorithm.

2. Cross-company cooperation is supported (e.g., suppliers and system integrators can exchange virtual "trial components" before signing contracts).

3. Every sub-system can be implemented in a tool that meets the particular requirements for the domain, the structure of the model and the simulation algorithm.

\section{Weaknesses:}

1. Computational performance of co-simulation compared to monolithic simulation.

2. Robustness of co-simulation compared to monolithic simulation.

3. Licenses for all programs are required to couple different simulation programs.

\section{Opportunities:}

1. Growing co-simulation community / growing industrial adoption.

2. Better communication between theoretical/numerical part, implementation and application/industry.

3. User-friendly tools (pre-defined master algorithms, integrated error estimation, sophisticated analysis to determine best parameterization of solvers and master algorithm).

\section{Threats:}

1. Insufficient knowledge/information of users in cosimulation may lead to improper use (e.g. wrong or missing error estimation, stability issues etc.).

2. Lack of exchange/cooperation between theoreti$\mathrm{cal} /$ numerical part, implementation and application/industry. 
3. Incompatibility of different standards and cosimulation approaches.

In addition, the experts were asked to name established standards or promising candidates for standards in cosimulation for continuous time, discrete event and hybrid co-simulation. The results show that the Functional Mockup Interface is considered the most promising standard in all three categories (see Figure 1).

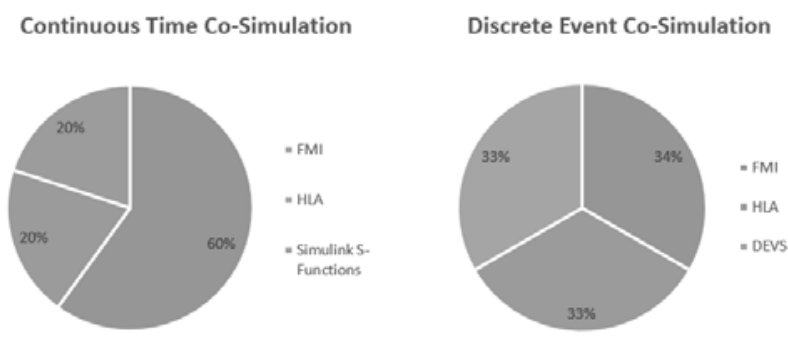

Hybrid Co-Simulation

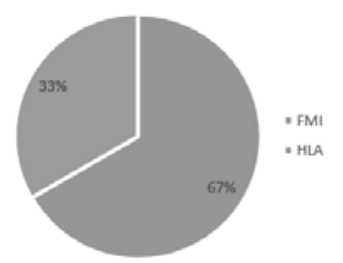

Figure 1: Established standards for co-simulation.

The experts' answers regarding their personal experience of difficulties with co-simulation are summarized in Figure 2.

Co-simulation is an omnipresent topic with evervarying challenges and openings for new research. An assessment of currently open research fields by the participating experts is shown in Figure 3.

\section{Conclusion}

The first results of this study confirm the assumption that depending on the primal discipline and field of application, research on co-simulation exhibits different perceptions of the definition, specific focus and importance of challenges as well as open research questions in co-simulation. However, commonalities emerge for certain problems and promising standards, which are to some extent already worked on by experts from different disciplines in international cooperation.

Final results of the survey can be found in [14] and [15].

\section{References}

[1] Atam E. Current software barriers to advanced modelbased control design for energy efficient buildings. Renewable and Sustainable Energy Reviews. 2017; 73: 1031-1040. doi: 10.1016/j.rser.2017.02.015.

[2] Clayton, M. J. Delphi: A technique to harness expert opinion for critical decision-making tasks in education. Educational Psychology. 1997; 17(4): 373-386. doi: 10.1080/0144341970170401.

[3] Dalkey N, Helmer O. An Experimental Application of the DELPHI Method to the Use of Experts. Management Science. 1963; 9(3): 351-515. doi: 10.1287/mnsc.9.3.458.

[4] Delbecq AL, Van de Ven AH, Gustafson DH. Group Techniques for Program Planning: A Guide to Nominal Groups and Delphi Process. Middleton: Green Briar Press; 1986.

[5] Gomes C, Thule C, Broman D, Larsen PG, Vangheluwe H. Co-Simulation: A Survey. ACM Computing Surveys. 2018; 51(3): 1-33. doi:10.1145/3179993

[6] Hsu C., Sandford B. The Delphi Technique: Making Sense of Consensus. Practical Assessment, Research \& Evaluation. 2007; 12.

[7] Kurttila M, Pesonen M, Kangas J, Kajanus M. Utilizing the analytic hierarchy process (AHP) in SWOT analysis - a hybrid method and its application to a forest-certification case. Forest Policy and Economics. 2000; 1(1): 41-52. doi: 10.1016/S1389-9341(99)00004-0.

[8] Oppelt M, Wolf G, Urbas L. Life Cycle Simulation for a Process Plant based on a Two-Dimensional Co-Simulation Approach. Computer Aided Chemical Engineering. 2015; 37: 935-940. doi: 10.1016/B978-0-444-63577-8.50001-2.

[9] Okoli C, Pawlowski SD. The Delphi method as a research tool : an example, design considerations and applications. Information \& Management. 2004; 72(1): 15-29. doi: 10.1016/j.im.2003.11.002.

[10] Reinsberger K, Brudermann T, Posch A. The role of photovoltaics in energy transition - Assessing the prospects for a regime shift. GAIA - Ecological Perspectives for Science and Society. 2015; 24(1): 41-47. doi: 10.14512/gaia.24.1.9.

[11] Stern T, Heil G, Ledl C, Schwarzbauer P. Identifying innovation barriers using a Delphi method approach: the case of technical lignin in the wood-based panel industry. International Wood Products Journal. 2012; 3(2): 116-123. doi: 10.1179/2042645312Y.0000000015. 


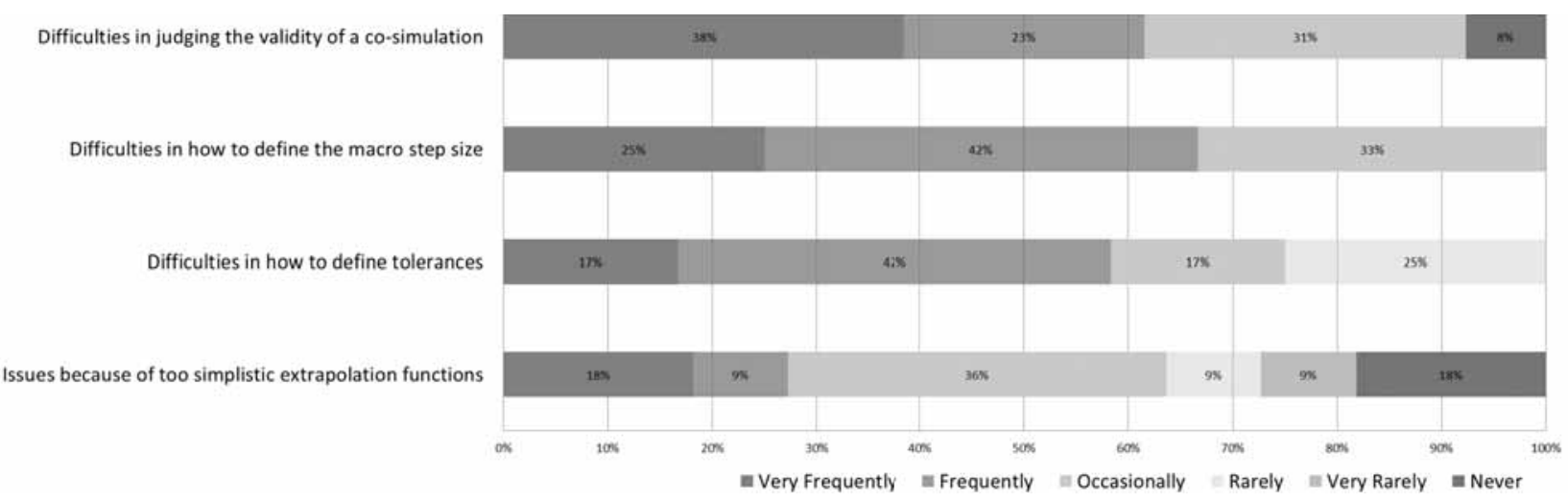

Figure 2: Experts' personal experience with co-simulation.

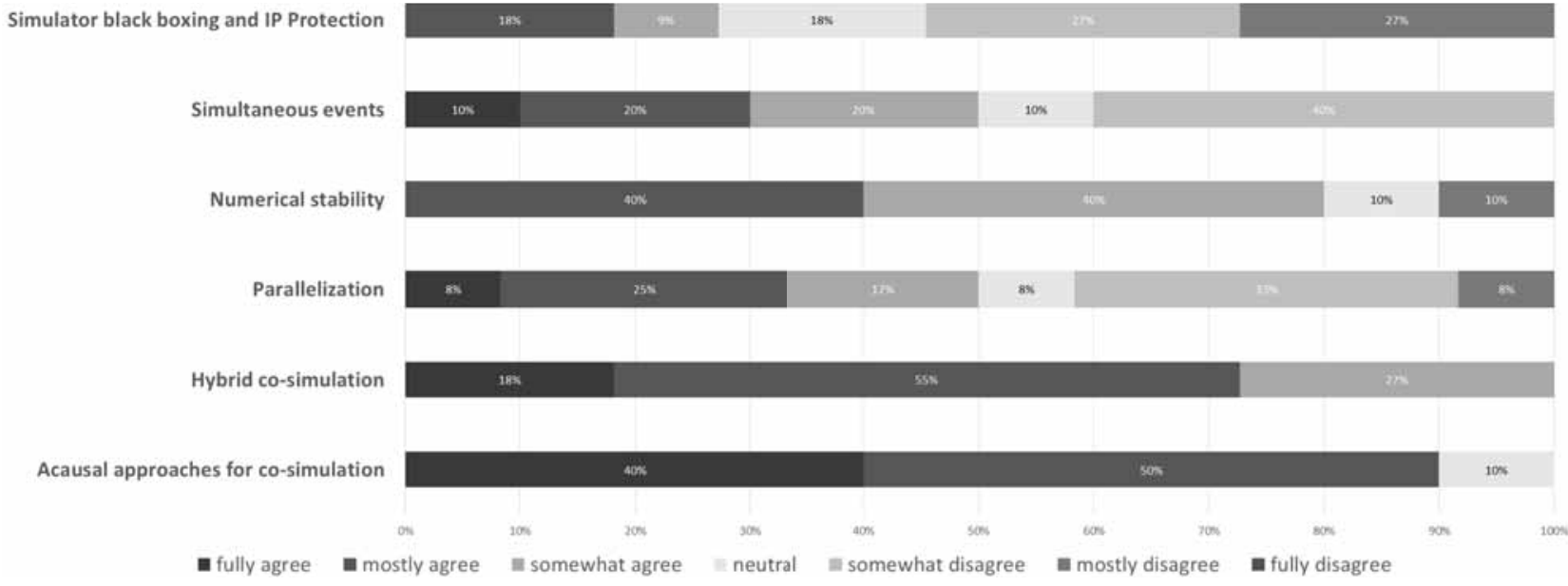

Figure 3: Open research fields in the area of co-simulation.

[12] Trcka M. Co-simulation for Performance Prediction of Innovative Integrated Mechanical Energy Systems [dissertation]. [Faculty of Architecture, Building and Planning, (The Netherlands)]. Technische Universiteit Eindhoven; 2008.

[13] Hafner I, Popper N. On the Terminology and Structuring of Co-simulation Methods Proceedings of the 8th International Workshop on Equation-Based Object-Oriented Modeling Languages and Tools. 2017; Weßling, Germany. doi: $10.1145 / 3158191.3158203$.

[14] Schweiger G,Gomes C, Engel G, Hafner I, Schoeggl J, Posch A, Nouidui T. Functional Mock-up Interface: An empirical survey identifies research challenges and current barriers. The American Modelica Conference 2018. 2018 Oct; Somberg Conference Center, Cambridge MA, USA. doi: 10.3384/ecp18154138.
[15] Schweiger G, Gomes C, Engel G, Hafner I, Schoeggl J, Posch A, Nouidui T. An Empirical Survey on Co-Simulation: Promising Standards, Challenges and Research Needs. Simulation Modelling Practice and Theory. 2019; 95(issue): 148-163. doi: 10.1016/j.simpat.2019.05.001.

[16] Schweiger G, Nilsson H, Schoeggl J, Birk W, Posch A. Modeling and simulation of large-scale systems: A systematic comparison of modeling paradigms Applied Mathematics and Computation. 2020; 365. doi: 10.1016/j.amc.2019.124713. 